\title{
VLOGA MENTORJA PRI UMETNIŠKEM USTVARJANJU V SKUPINI ODRASLIH Z MOTNJO V DUŠEVNEM RAZVOJU
}

\section{POVZETEK}

Prispevek predstavlja ugotovitve raziskave, ki se je osredotočala na vlogo mentorja pri umetniškem ustvarjanju v skupini odraslih z motnjo $v$ duševnem razvoju. Podatki so bili zbrani v obdobju 2014-2016 z. metodo opazovanja z udeležbo ter s pomočjo polstrukturiranih intervjujev z mentorji. Raziskava izhaja iz predpostavke, da je umetniško ustvarjanje pomemben del življenja in izobraževanja oseb z motnjo v duševnem razvoju. Vloga mentorja, ki vodi skupino oseb z motnjo v duševnem razvoju, se razlikuje od vloge mentorja $v$ skupinah oseb brez motnje $v$ duševnem razvoju. Rezultati raziskave so predstavljeni po sklopih, ki zajemajo ugotovitve o izbranih področjih delovanja mentorja: motiviranje skupine, vodenje, spodbujanje samostojnosti udeležencev, individualizacija in prilagajanje procesa udeležencem, prilagajanje aktivnosti dejanski starosti oseb z motnjo $v$ duševnem razvoju, vključevanje udeležencev $v$ nastajanje procesa, kombiniranje različnih aktivnosti.

Ključne besede: mentorstvo, metode izobraževanja, osebe s posebnimi potrebami, timsko delo, participacija

\section{THE ROLE OF THE MENTOR IN CREATIVE ARTS ACTIVITIES IN A GROUP OF ADULTS WITH INTELLECTUAL DISABILITIES - ABSTRACT}

The article presents the findings of research on the mentor's role in creative arts activities in a group of adults with intellectual disabilities. Over the period between 2014-2016, data has been collected employing the participant observation method and semi-structured interviews with mentors. The research proceeds from the assumption that creative arts play an important part in the life and education of a person with intellectual disabilities. The role of a mentor, who leads a group of people with intellectual disabilities, differs from the role of a mentor in a group of people without intellectual disabilities. The results of the study are presented in subsets which encompass the findings related to the following fields of mentor activities: group motivation, guidance, promoting participant independence, individualization and adaptation of the process to the needs of the participants, adjusting the activities to the actual age of the person with intellectual disabilities, involvement of participants in the formation of the process, and combination of different activities.

Keywords: mentorship, educational methods, persons with special needs, team work, participation 


\section{UVOD}

Osebe s posebnimi potrebami so še vedno ena izmed skupin, ki ostaja na robu družbe in je pogosto izključena iz družbenega življenja, nameščena v ločene institucije (Rutar, 2015; Kroflič, 2014). Ponudba izobraževanja ${ }^{1}$ je zanje veliko manjša kot za večinsko populacijo. In če koncept vseživljenjskega učenja, kot ga uveljavljajo politični dokumenti, npr. Lizbonska strategija, Konvencija o pravicah invalidov (2006), in različni raziskovalci (prim. Aspin, Chapman, Evans in Bagnall, 2012), poudarjajo enake možnosti za vse, potem bi morali oblikovati tudi izobraževalne možnosti, ki bi bile prilagojene značilnostim posebnih ciljnih skupin. Vseživljenjsko učenje, ki vključuje vse skupine in deluje inkluzivno, pomembno vpliva na razvoj vsakega posameznika in družbe kot celote. Za ta namen se razvijajo različne strategije izobraževanja. V sodobnosti so najbolj znane metode, povezane z e-izobraževanjem in novimi tehnologijami, mnoge pa so povezane tudi z umetnostjo. ${ }^{2}$ Oboje se uveljavlja tudi pri delu s skupinami s posebnimi potrebami. Namen naše raziskave je bil ugotoviti, kakšna je vloga mentorja pri vpeljevanju različnih metod umetniškega ustvarjanja v skupini odraslih z motnjo v duševnem razvoju.

\section{Osebe s posebnimi potrebami in načini vključevanja v družbo}

Besedna zveza »oseba s posebnimi potrebami« se navadno uporablja za ljudi z nekim primanjkljajem (slepi, slabovidni, gibalno ovirani, ljudje po poškodbi glave, ljudje z motnjo v duševnem razvoju idr.). V slovenskem prostoru zasledimo uporabo različnih izrazov: invalid, oseba $\mathrm{z}$ invalidnostjo, hendikepirani, funkcionalno ovirane osebe, osebe s posebnimi potrebami. V strokovni literaturi ni soglasja o poimenovanju. Rutar (2015) in Kačič, Bavčar in Sudec Bednařik (2015) uporabljajo termin hendikepirani, Brecelj, Vidmar in Boštjančič (2014) uporabljajo termin invalid ali osebe z invalidnostjo, Dremelj (2009) in Gorjup (2006) pišeta o osebah s posebnimi potrebami, Žagar (2012) pa o drugačnih učencih.

Slovenska zakonodaja kot skupine oseb s posebnimi potrebami opredeljuje tiste skupine oseb, ki med svojim razvojem, pa tudi kasneje, potrebujejo določene oblike pomoči ali prilagoditev, ki omogočijo razvoj njihovih potencialov v največji možni meri. Zakon o izenačevanju možnosti invalidov (2010) opredeljuje invalide kot osebe z dolgotrajnimi telesnimi, duševnimi in senzoričnimi okvarami ter motnjami v duševnem razvoju, ki jih v povezavi z različnimi ovirami lahko omejujejo, da bi enako kot drugi polno in učinkovito sodelovali v družbi. Med osebe s posebnimi potrebami uvrščamo:

- osebe z motnjami v duševnem razvoju,

- slepe in slabovidne osebe oziroma osebe z okvaro vidne funkcije,

- gluhe in naglušne osebe,

1 Z besedo izobraževanje bomo označevali namerno organizirano dejavnost, intencionalno vpeljevanje procedur, ki omogočajo učenje. $\mathrm{Z}$ besedo učenje bomo označevali procese učenja, ki se dogajajo, a niso posebej načrtovani.

2 Brookfield (2013) v svojem delu metodam poučevanja odraslih namenja posebno poglavje za opis uporabe umetnosti pri poučevanju (Teaching using the creative arts). 
- $\quad$ osebe z govorno-jezikovnimi motnjami,

- gibalno ovirane osebe,

- dolgotrajno bolne osebe,

- $\quad$ osebe s primanjkljaji na posameznih področjih učenja,

- $\quad$ osebe z avtističnimi motnjami ter

- $\quad$ osebe s čustvenimi in vedenjskimi motnjami (Vovk-Ornik, 2015).

Polno in učinkovito sodelovanje ter vključenost v družbo je eno od splošnih načel Konvencije o pravicah invalidov (2006). Skupine oseb s posebnimi potrebami na različne načine vključujemo v družbo ter s tem spodbujamo sprejemanje in razumevanje drugačnosti. Odnos do drugačnosti je namreč »temeljni katalizator razvoja aktivne strpnosti in inkluzivne kulture skupnosti«, piše Kroflič (2006, str. 28). Naj omenimo nekaj projektov, ki smo jih v zadnjih letih zasledili v Sloveniji na področju vključevanja oseb s posebnimi potrebami: Zveza društev za cerebralno paralizo Slovenije Sonček že od leta 1993 izvaja projekt »Korak k sončku «, ${ }^{3}$ Center za usposabljanje, delo in varstvo Dolfke Boštjančič Draga (CUDV Draga) je dal pobudo za odprtje gostilnice Druga violina, ki deluje od leta 2013, Zavod za slepo in slabovidno mladino Ljubljana (ZSSM Ljubljana) organizira projekt »Večerja v temi «, ${ }^{4}$ Center za izobraževanje, rehabilitacijo in usposabljanje Kamnik (CIRIUS Kamnik) je v letih 2009-2012 sodeloval pri projektu aktivendrzavljan.si. ${ }^{5} \mathrm{Na}$ področju vključevanja oseb s posebnimi potrebami v družbo imamo tudi številne objave (Kobal Grum in Kobal, 2009; Majerhold, 2014; Rutar, 2015; Založnik, 2006).

\section{Značilnosti oseb z motnjo $\mathrm{v}$ duševnem razvoju in njihove možnosti za vključevanje v družbo}

V članku se osredotočamo na osebe z motnjo v duševnem razvoju. Definicij motnje v duševnem razvoju je več. V sodobnosti se široko uporablja definicija Ameriškega združenja za mentalno retardacijo, pri kateri Žagar (2012) poudarja tri vidike: (1) podpovprečno intelektualno delovanje (IQ pod 75), (2) omejitve v adaptivnem vedenju in (3) razvojno obdobje od rojstva do 18. leta starosti. Zavod RS za šolstvo uporablja opredelitev, po kateri je motnja $v$ duševnem razvoju nevrološko pogojena razvojna motnja, ki se pokaže pred dopolnjenim 18. letom starosti, osebe $\mathrm{z}$ motnjo v duševnem razvoju pa so tiste, ki imajo pomembno manjše intelektualne sposobnosti (splošno inteligenco, sposobnosti učenja, sklepanja in reševanja problemskih okoliščin, sposobnosti abstraktnega mišljenja in presojanja) ter pomembna odstopanja prilagoditvenih spretnosti (Marinč idr., 2015). Osebe z motnjo v duševnem razvoju so torej tiste, ki imajo znižano splošno ali specifično raven

3 Opis projekta »Korak k sončku« je dostopen na: http://www.soncek.org/kaj-delamo/izobrazevanje/ena-sola-za-vse/projekt-korak-k-soncku/.

4 Dušak, D. (b. 1.). Projekt: Večerja v temi - Kako in kaj delamo, kaj smo se naučili in kaj se še moramo naučiti. Pridobljeno s http://582.gvs.arnes.si/wordpress/wp-content/uploads/2015/11/ve\%C4\%8Derja-v-temi-OPIS.pdf.

5 Opis in potek projekta aktivendrzavljan.si je dostopen na: http://www.cirius-kamnik.si/projekti/projekt_ aktiven_drzavljan. 
inteligentnosti, manjše sposobnosti na kognitivnem, govornem, motoričnem in socialnem področju ter pomanjkanje veščin, kar povzroča neskladje med njihovo mentalno in kronološko starostjo (Može Cedilnik in Uršnik, 2011).

Motnje v duševnem razvoju so lahko kombinirane z drugimi razvojnimi motnjami, stopnjo motnje pa določimo glede na skupni rezultat IQ ter na podlagi ugotovljenih prilagoditvenih funkcij. Tako ločimo osebe $\mathrm{z}$ lažjo, zmerno, težjo in težko motnjo v duševnem razvoju (Marinč idr., 2015). Motnja v duševnem razvoju je vseživljenjski problem. Zaradi zmanjšanih intelektualnih sposobnosti posamezniki niso nikoli popolnoma samostojni, kar pa ne pomeni, da se ne morejo učiti, izražati, napredovati.

Skupina oseb z motnjo v duševnem razvoju je večinoma izključena iz širše družbe, saj je to edina skupina oseb s posebnimi potrebami, ki se ne more šolati v splošni osnovni šoli. Zanje pripravljajo prilagojen in poseben program vzgoje in izobraževanja. ${ }^{6}$ Čeprav ti izobraževalni programi individualno obravnavajo vsakega posameznika in so skupini oseb z motnjo v duševnem razvoju prilagojeni, pa te posameznike ločujejo od preostalih otrok in mladostnikov. Ko osebe z motnjo v duševnem razvoju odrastejo, so večinoma še vedno izključene iz širše družbe. Večina jih živi v centrih za usposabljanje, delo in varstvo (CUDV), varstveno-delovnih centrih (VDC) ali pa v stanovanjskih skupinah, zgolj redki so v organizacijah skupaj z drugimi ljudmi.

Ena izmed dobrih praks vključevanja oseb z motnjo v duševnem razvoju v družbo v Sloveniji je gostilnica Druga violina, v kateri strežejo ljudje s posebnimi potrebami in po tej poti razbijajo predsodke o svoji nezmožnosti. Ena od možnosti vključevanja oseb z motnjo v duševnem razvoju v družbeno okolje je tudi tista, ki jo daje umetnost. Tako so v letu 2010 na Centru za izobraževanje, rehabilitacijo in usposabljanje Vipava (CIRIUS Vipava) pripravili plesno predstavo Rdeči čeveljčki, ${ }^{7}$ februarja 2016 je bil 3. festival Tantadruj, ${ }^{8}$ maja 2016 pa 10. mednarodni festival »Igraj se z mano «. ${ }^{9}$

\section{Umetniško ustvarjanje ${ }^{10} \mathrm{v}$ skupini oseb z motnjo v duševnem razvoju}

Vpetost v umetniško ustvarjanje je danes pogosto v ozadju, saj v izobraževanju v ospredje prihajajo različne družboslovne in naravoslovne vede, ki po sodobnih kulturnih merilih prinašajo uporabnejša znanja, omogočajo zaposlitev in se prilagajajo trgu dela. Umetniško

6 V prilagojeni program so vključene osebe $\mathrm{z}$ lažjo motnjo $\mathrm{v}$ duševnem razvoju, $\mathrm{v}$ posebni program pa tiste z zmerno, težjo ali težko.

7 Plesno predstavo Rdeči čeveljčki je pripravila plesna skupina Vrtiljak v sodelovanju z M\&N Dance Company in plesnim klubom TERPSIHORA Šempeter Vrtojba.

8 Festival Tantadruj je srečanje gledaliških skupin oseb z motnjami v duševnem razvoju, ki ga organizira CUDV Draga. Opis in program festivala, ki je bil 1. februarja 2016, je dostopen na: http://www.spanskiborci. si/7/903/festival-tantadruj.html.

9 Mednarodni festival »Igraj se z mano« spodbuja socialno integracijo in inkluzijo oseb s posebnimi potrebami. Pridobljeno s http://www.igrajsezmano.eu/

10 Izraz umetniško ustvarjanje bomo uporabljali za skupek vseh vrst ustvarjanja: likovno, glasbeno, plesno-gibalno, dramsko in lutkovno. 
ustvarjanje pa je - kljub zanemarjenosti - zelo pomembno v življenju vseh ljudi in še posebno oseb s posebnimi potrebami. Osebe s posebnimi potrebami so z umetnostjo povezane kot ustvarjalci, izvajalci, prenašalci in/ali uporabniki umetniških del (Kačič idr., 2015). Razvoj in uporabo ustvarjalnih ter umetniških sposobnosti poudarja tudi Konvencija o pravicah invalidov (2006). Ker imajo osebe z motnjo v duševnem razvoju pogosto težave tudi na govornem področju (Može Cedilnik in Uršnik, 2011; Novljan in Jelenc, 2000), se večina med njimi lažje izraža skozi neverbalno komunikacijo, kar jim lahko omogočimo $\mathrm{z}$ umetniškim ustvarjanjem.

Umetniško ustvarjanje je človekova lastnost, ni omejena na nekatere posameznike, ampak imamo to sposobnost in potrebo vsi ljudje (Kroflič, 2015). Ustvarjanje je pogosto opredeljeno kot izražanje nečesa, kar je v družbi sprejeto kot »nenormalno«, neobičajno, marginalizirano, diskriminirano, celo nadčloveško (Kačič idr., 2015), saj gre pri ustvarjalnosti za oblikovanje nečesa novega, kar okolje preseneti.

Umetnost je eden najprimernejših medijev za razvoj identitete, sebstva in moralne samopodobe (Kroflič, Štirn Koren, Štirn Janota in Jug, 2010). Umetnost je neulovljiva in osebna ter kot taka omogoča drugačnost in osebno izražanje (Gorjup, 2006), zaradi česar menimo, da je pomemben del življenja oseb z motnjo v duševnem razvoju. Izdelek poleg zavednega izraža tudi nezavedno, zato je umetnost izjemno pomembna, ko raziskujemo čustva, občutke in odnose, pa tudi duhovne razsežnosti, misli in ideje, ki jih posameznik izraža ob ustvarjanju (Kroflič, 2015; Gorjup, 2006). Za osebe z motnjo v duševnem razvoju ima velik pomen tudi zato, ker jim skozi umetniško ustvarjanje omogoča svobodo (Kačič idr., 2015; Kroflič, 2015).

Zaradi tega menimo, da je pomembno spodbujati ustvarjalnost oseb z motnjo v duševnem razvoju prek različnih umetniških dejavnosti, kot so likovno ustvarjanje, dramska igra, glasbene delavnice (petje, igranje inštrumentov), plesno-gibalno ustvarjanje idr. Uporaba izobraževalnih strategij z umetnostjo pa implicira tudi delovanje mentorja v skupini.

\section{Mentor v skupini oseb z motnjo v duševnem razvoju}

Mentorstvo razumemo kot proces, v katerem izkušena oseba podpira, pomaga in vodi manj izkušeno osebo pri razvoju znanja in veščin ter pri poklicni in osebnostni rasti (Klinge, 2015), mentorja pa kot tistega, ki ima znanje in izkušnje o nekem strokovnem področju, zaradi česar lahko mentorirancu svetuje, ga poučuje, vodi, spremlja, podpira, usmerja, spodbuja, motivira (Findeisen, 2012). Izkušnje in znanje na nekem področju so ena od pomembnih lastnosti mentorja. V naši raziskavi je to področje delovanja $\mathrm{z}$ umetnostjo. Mentor ima tako različne vloge: je spodbujevalec, vzornik, motivator, podpornik in/ali svetovalec (Opalk, 2003). Biti mora čim bolj demokratičen, odločen, ustvarjalen in samozavesten, mentoriranec pa mu mora zaupati (Govekar-Okoliš in Kranjčec, 2012, 2013). Tudi skupino oseb z motnjo v duševnem razvoju in vsakega posameznika v skupini mentor vodi skozi umetniško ustvarjanje, jih usmerja ter jim pomaga pri izražanju njihovih umetniških potencialov. 
V slovenskem prostoru nismo zasledili člankov in raziskav o mentorstvu $\mathrm{v}$ skupini odraslih $\mathrm{z}$ motnjo $\mathrm{v}$ duševnem razvoju, $\mathrm{v}$ tujini pa $\mathrm{v}$ zadnjih letih pogosteje raziskujejo to področje in najdemo lahko objave o mentorstvu odraslim z motnjo v duševnem razvoju v visokošolskem izobraževanju (Farley, Gibbons in Cihak, 2014; Giust in Valle-Riesta, 2014). Avtorji poudarjajo pomen vrstniških, medsebojnih mentorjev (peer supporter mentor), o katerih pišejo tudi Savage idr. (2013). Raziskave na področju mentorstva se v zadnjih letih usmerjajo tudi v aktivno mentorstvo za starejše osebe z motnjo v duševnem razvoju (prim. Chng, Stancliffe, Wilson in Anderson, 2013; Wilson idr. 2013).

Na podlagi navedenega smo oblikovali ključno raziskovalno vprašanje, kakšno vlogo ima mentor pri umetniškem ustvarjanju $\mathrm{v}$ skupini odraslih $\mathrm{z}$ motnjo $\mathrm{v}$ duševnem razvoju in katere so značilnosti njegovega delovanja.

\section{METODOLOGIJA}

Osnovna metodološka paradigma je bila kvalitativna. V raziskavi smo za zbiranje podatkov uporabili metodo opazovanja z udeležbo. V novembru in decembru 2014 smo aktivno sodelovali na likovnih delavnicah za skupino odraslih z motnjo $\mathrm{v}$ duševnem razvoju in opazovali vlogo mentorja v procesu ustvarjanja. Pri ustvarjanju so sodelovali odrasli z zmerno, težjo in težko motnjo $\mathrm{v}$ duševnem razvoju, med katerimi je večina potrebovala vodenje z roko ena na ena. V tem času smo pisali dnevnik dogajanja. V letih 2015 in 2016 smo zbirali podatke s pomočjo intervjujev. Izvedli smo pet polstrukturiranih intervjujev $\mathrm{s}$ strokovnimi delavci, ki na različne načine ustvarjajo $\mathrm{z}$ osebami z motnjo $\mathrm{v}$ duševnem razvoju. Pripravili smo opomnik za intervju, v katerega smo vključili odprta vprašanja, ki smo jih med potekom intervjuja dopolnjevali s podvprašanji (Josselson, 2013). Dva intervjuja sta bila izvedena v letu 2015, trije pa v letu 2016. Med intervjuvanci so bile tri ženske, ki z osebami z motnjo v duševnem razvoju ustvarjajo glasbeno, likovno, plesno-gibalno in/ali dramsko. Dva intervjuvanca sta bila moška. Oba z osebami z motnjo v duševnem razvoju izvajata gledališke predstave. Podatke, ki smo jih pridobili z intervjuji in opazovanjem z udeležbo, smo obdelali po metodi utemeljene teorije (grounded theory), ki vključuje natančen opis podatkov in konteksta (Flick, 2014). Podatke smo analizirali in klasificirali s tehniko kodiranja zapisov.

Da bi dobili odgovor na ključno vprašanje, smo tega razčlenili na naslednja raziskovalna vprašanja:

- Katere elemente zajema vloga mentorja, ki umetniško ustvarja s skupino oseb z motnjo v duševnem razvoju?

- Na kaj je mentor pozoren pri umetniškem ustvarjanju v skupini oseb z motnjo v duševnem razvoju?

- Katere so značilnosti uspešnega mentorja pri umetniškem ustvarjanju v skupini oseb $\mathrm{z}$ motnjo v duševnem razvoju?

- Katere naloge ima mentor pri umetniškem ustvarjanju v skupini oseb z motnjo v duševnem razvoju? 
Ko smo analizirali dnevniške zapise in prepise intervjujev, smo glede na zgornja vprašanja oblikovali posamezne kategorije.

\section{REZULTATI IN INTERPRETACIJA}

Rezultate kvalitativne raziskave bomo prikazali in analizirali po sklopih, ki zajemajo ključne ugotovitve glede na posamezne kategorije:

- mentor kot motivator,

- mentor kot vodja in pomočnik ter timsko delo kot dejavnik izvedbe,

- mentor kot spodbujevalec ter krepitev samostojnosti oseb z motnjo v duševnem razvoju,

- individualizacija in prilagajanje procesa,

- prilagajanje aktivnosti dejanski starosti oseb z motnjo v duševnem razvoju,

- participacija oseb z motnjo v duševnem razvoju,

- zaupanje, pohvala ter realni cilji kot ključni elementi uspešnega mentorstva,

- kombiniranje različnih aktivnosti kot pogoj za krepitev samozavesti, samostojnosti ter socialne vključenosti.

Skladno z značilnostmi podajanja rezultatov kvalitativne raziskave (Flick, 2014; Josselson, 2013) bomo ob opisovanju podatkov, ki smo jih pridobili z našo empirično raziskavo, sproti interpretirali in primerjali rezultate tudi z drugimi viri.

\section{Mentor kot motivator}

Ko smo skupaj z osebami z motnjo v duševnem razvoju ustvarjali na likovnem področju, smo ugotovili, da je pred vsako dejavnostjo pomembno motiviranje skupine in vsakega posameznika, kar potrjujejo tudi intervjuvanci: »Osebe z motnjo v duševnem razvoju bodo namreč sodelovale šele takrat, ko bomo pritegnili njihovo pozornost ter vzbudili $v$ njih zanimanje za ustvarjanje. «11 [Intervjuvanec 3] ${ }^{12}$

Iz zapisov intervjujev in opazovanja smo ugotovili, da je zelo pomemben element mentorjeve vloge zmožnost motiviranja skupine. Osebe z motnjo v duševnem razvoju za svoj razvoj potrebujejo stimulacijo (Grubešič, 2014), zato je pred vsakim ustvarjanjem treba vzbuditi zanimanje za ustvarjanje in željo po njem, kar lahko poteka na različne načine. Mentor navadno skupini razloži, kaj in kako bodo ustvarjali, pri tem mora biti njegova razlaga čim bolj jasna in razumljiva za udeležence. ${ }^{13}$ Če je razlaga preveč abstraktna ali preveč zahtevna za udeležence v skupini, posameznika ne bo motivirala za ustvarjanje.

11 Intervjuvanci so na vprašanja odgovarjali zelo specifično - nekateri so se izražali strokovno, drugi so uporabljali umetniški jezik. Poleg tega so posamezniki govorili v narečnem, pogovornem jeziku. Za namen raziskave smo citate preoblikovali in jih zapisali v knjižni slovenščini.

12 Da bi ohranili nevtralnost pri zapisih, smo za vse intervjuvance uporabili moški slovnični spol.

13 Že Brajša (1983) postavlja jasno komunikacijo na sam vrh seznama lastnosti učinkovitega mentorja, kar velja za vsa okolja. Poudarja, da mora biti njegova komunikacija koherentna - verbalno in vedenjsko mora izražati prav tisto, kar dejansko misli in čuti, saj zgolj tako pridobi zaupanje mentoriranca. Podobno najdemo tudi v sodobnih virih o mentorstvu (Allen in Eby, 2010; Govekar-Okoliš in Kranjčec, 2012, 2013). 
Motiviranje posameznikov ni enostavno, zato mora biti mentor ustvarjalen pri izboru svojih metod, saj posameznike motivirajo različne stvari. Nekoga lahko motivirajo stiki v skupini ne glede na vsebino (Novljan in Jelenc, 2000), drugi pa potrebujejo dodatno motiviranje pred vsakim srečanjem in tudi med njim.

\section{Mentor kot vodja in pomočnik ter timsko delo kot dejavnik izvedbe}

Kot pomemben element pri vlogi mentorja se je izkazala zmožnost motiviranja skupine. Drugi pomemben element pa je zmožnost vodenja procesa in skupine ter razvijanja timskega dela.

Intervjuvanci poudarjajo, da je stopnja pomoči in vodenja odvisna od posameznikove stopnje motnje $\mathrm{v}$ duševnem razvoju ter njegovih prirojenih in pridobljenih težav. Intervjuvanec 2: »Nekateri pri tem ne potrebujejo nobene pomoči, drugi verbalno spodbudo, nekateri pa vodenje $z$ roko.«Podobno razlagajo tudi drugi intervjuvanci. Intervjuvanec 3 o gledališki dejavnosti: »Ko gre za osebe z zmernimi in težjimi motnjami $v$ duševnem razvoju, skoraj vsak izmed njih potrebuje tudi individualno vodstvo, saj so zelo redki med njimi taki, ki bi bili lahko samostojni na odru.«

Tudi pri likovnem ustvarjanju smo z udeleženci delali po metodi ena na ena, saj je kar nekaj udeležencev imelo težave na področju fine motorike.

Naslednja podkategorija, ob kateri so se zbirale kode, je zmožnost mentorja, da razvija timsko delo $\mathrm{z}$ drugimi udeleženci, ki so pomočniki osebam z motnjo $\mathrm{v}$ duševnem razvoju. Intervjuvanec 3: »Izredno dobrodošle so razne pomoči določenih prostovoljnih skupin. /... Če se ustvari ena taka ekipa ljudi, kjer bi se lahko primarno res delalo ena na ena, lahko vključiš tudi tiste, ki potrebujejo absolutno vodenje.«

Analiza intervjujev in opazovanja je pokazala, da je mentor predvsem tisti, ki ponuja pomoč in vodi, kar potrjujejo tudi ugotovitve iz drugih raziskav (npr. Allen in Eby, 2010; Findeisen, 2012; Opalk, 2003). Osebe z motnjo v duševnem razvoju so si med seboj zelo različne, zaradi česar potrebujejo tudi različne stopnje pomoči in vodenja. Osebe z lažjo in zmerno motnjo v duševnem razvoju so bolj samostojne, osebe s težjo in težko motnjo pa potrebujejo več pomoči (Može Cedilnik in Uršnik, 2011; Žagar, 2012). Pogosta je tudi sopojavnost čustveno-vedenjskih težav, govorno-jezikovnih motenj, težav na gibalnem področju, v motoriki (Novljan in Jelenc, 2000; Može Cedilnik in Uršnik, 2011). Zaradi tega je pomembno, da se ustvari tim, $v$ katerega so vključeni mentorji s strokovnim znanjem na področju specialne pedagogike in didaktike ter drugi pomočniki prostovoljci. Tako zagotovimo mentorsko delo za celotno skupino.

Timsko delo v skupini oseb brez motnje v duševnem razvoju ni tako izrazito, saj lahko posamezniki razmeroma samostojno izvajajo aktivnosti, $\mathrm{v}$ skupini oseb $\mathrm{z}$ motnjo $\mathrm{v}$ duševnem razvoju pa je izredno pomembno, predvsem za vključitev oseb z zmerno, težjo in težko motnjo v duševnem razvoju. 


\section{Mentor kot spodbujevalec in krepitev samostojnosti oseb $z$ motnjo $v$ duševnem razvoju}

Intervjuvanci menijo, da lahko umetniško ustvarjanje pozitivno vpliva na razvoj samostojnosti oseb z motnjo v duševnem razvoju, zato je pomembno, da jim samostojnost tudi omogočamo. Intervjuvanec 3: »Mi največjo napako delamo takrat, kadar delamo preveč stvari namesto njih. I.../ Najlepše je, če mu daš možnost, da se sam preizkusi, ter tako vidiš, kje je in kaj zmore.«Pri tem je pomembno, da mentor osebe z motnjo v duševnem razvoju spodbuja skozi celoten proces, kar poudarjajo tudi intervjuvanci.

»Sam predvsem glasbeno ustvarjam z njimi (prepevamo ob kitari). Tudi tam velja, da kar znajo, znajo, se sicer marsičesa lahko naučijo, vendar ob spodbudi in nekako nezavedno.« [intervjuvanec 1]

Analiza je pokazala, da mora mentor osebe z motnjo v duševnem razvoju spodbujati skozi celoten proces in jim dajati možnosti za čim večjo samostojnost. Preprečevanje samostojnosti, če so je posamezniki z motnjo v duševnem razvoju zmožni, te osebe psihično in mentalnohigiensko obremenjuje (Novljan in Jelenc, 2000). Mentor naj bi znal oceniti (z uporabo različnih metod), kolikšne samostojnosti so osebe z motnjo v duševnem razvoju zmožne, in jih nato spodbujati, da samostojnost razvijajo. Čim večja samostojnost vsakega posameznika je eden izmed pomembnih ciljev, ki mu mora mentor slediti, ko dela z osebami z motnjo v duševnem razvoju.

\section{Individualizacija in prilagajanje procesa}

Mentor mora proces umetniškega ustvarjanja individualizirati, prilagoditi zmožnostim in stopnji oviranosti ter željam in interesom oseb z motnjo v duševnem razvoju. Naši sogovorniki izjavljajo, da je prilagajanje procesa umetniškega ustvarjanja osebam z motnjo v duševnem razvoju ena izmed njihovih pomembnejših in obsežnejših nalog. To mnenje smo zasledili v vseh intervjujih.

Intervjuvanec 1 (z vidika likovnega ustvarjanja): »Potrebno je pogledati sposobnosti vsakega posameznika, kakšno telesno poškodbo ima, ali sploh lahko drži čopič, barvice ali je bolje, da ustvarja s prstnimi barvami.«

Intervjuvanec 5 (z vidika dramskega ustvarjanja): »Potrebno je prilagoditi vse vaje. Osebe z motnjo $v$ duševnem razvoju so namreč verbalno zelo šibke. Težko se jih razume. Marsikatera predstava je recimo prilagojena tako, da ni teksta ali pa je vnaprej posnet.«

Intervjuvanec 3 (z vidika dramskega ustvarjanja): »Kako mu prilagoditi zadeve, da bo lahko na odru sam držal neko stvar, ali pa, kako prilagoditi kostum, da ga ne bo oviral. Pa tudi recimo, kako poenostaviti neko besedilo, da se ga bo lahko sam naučil, kako mu prišepniti, če ga bo pozabil.«

V zadnjem času se v vzgoji, izobraževanju in učenju na vseh stopnjah vedno bolj poudarja individualizacija (Dremelj, 2009; Krajnc, 2012), ta pa v skupini oseb z motnjo v duševnem razvoju pride še posebej do izraza. Analiza intervjujev in opazovanja kaže, da se izjemno 
pomembno in zahtevno delo mentorja nanaša na prilagajanje metod, tehnik, pripomočkov ter samega procesa zmožnostim vsakega posameznika, njegovi stopnji oviranosti ter hkrati njegovim željam in interesom. Potrdimo lahko ugotovitve drugih avtorjev (Gorjup, 2006; Može Cedilnik in Uršnik, 2011; Žagar, 2012). Strinjamo se s Krajnčevo (2012), da je pomembno, da mentor opazi posameznikova močna področja, na katerih gradi ves proces ustvarjanja. Tudi osebe z motnjo v duševnem razvoju imajo svoja »močna področja« in prav na teh mentor gradi proces ustvarjanja. Proces prilagajanja ustvarjanja osebam z motnjo v duševnem razvoju terja od mentorja precej ustvarjalnosti pri delu.

Individualizacija in prilagajanje procesa posameznim osebam z motnjo v duševnem razvoju pomeni za mentorja nenehno učenje na delovnem mestu in razvoj profesionalnih zmožnosti.

\section{Prilagajanje aktivnosti dejanski starosti oseb z motnjo v duševnem razvoju}

Intervjuvanci postavljajo $\mathrm{v}$ ospredje, da moramo z odraslimi z motnjo v duševnem razvoju delati v skladu z njihovo dejansko starostjo. Intervjuvanec 3: »Previdni moramo biti, da aktivnosti, ki jih pripravljamo zanje, ne pootročimo. Tako ne boš dal nekomu, ki ima 20 let, plesati račke ali pa miki miške, ampak boš prilagodil aktivnost njihovi dejanski starosti.«

Naši sogovorniki svoje dejavnosti prilagajajo dejanski starosti oseb z motnjo v duševnem razvoju, kar se kaže kot pomembna naloga mentorja. Ker gre za odrasle z motnjo v duševnem razvoju, jih mora mentor obravnavati kot odrasle ne glede na njihove sposobnosti in spretnosti (Tratnjek in Hameršak, 2004). Aktivnosti mora tako prilagoditi njihovim zmožnostim ter hkrati tudi njihovi starosti, na kar je opozorila že Jelenc Krašovec (2005).

Ko umetniško ustvarjamo z odraslimi brez motnje v duševnem razvoju, je izvajanje aktivnosti, primernih za odrasle, samoumevno, pri umetniškem ustvarjanju v skupini odraslih $\mathrm{z}$ motnjo $\mathrm{v}$ duševnem razvoju pa mora mentor temu nameniti posebno pozornost.

\section{Participacija oseb z motnjo v duševnem razvoju}

Ena izmed nalog mentorja je tudi vključevanje oseb z motnjo v duševnem razvoju v celoten proces umetniškega ustvarjanja. Intervjuvanec 3: »Veliko jim pomeni, če mentor pred delavnico izbere enega pomočnika med osebami z motnjo v duševnem razvoju. /.../ Na ta način, ko lahko sami vplivajo na celoten proces, ko lahko o stvareh odločajo, se počutijo pomembne.«Kljub temu pa intervjuvanci pravijo, da osebe z motnjo v duševnem razvoju običajno niso vključene $\mathrm{v}$ proces odločanja in načrtovanja.

»Zgodbo si zamisli specialna pedagoginja, ki z njimi dramsko ustvarja. Tudi vloge si ponavadi tako zamisli, da so prilagojene posamezniku, ki jo bo odigral. Ker jih že toliko pozna, da ve, kaj bo kdo izmed njih zmogel. Tako se jim ona približa, ne da bi sami raziskovali.«[intervjuvanec 5]

Kot opažajo intervjuvanci, je pri ustvarjanju z osebami z motnjo v duševnem razvoju pomembno, da jih mentor sprejme take, kot so: »Če ne upoštevamo njihovih želja in jim ne 
pustimo, da so, kar so, da ustvarjajo v skladu s tem, kar so, da sami ustvarjajo zgodbo, potem zatremo tisto ustvarjalno $v$ njih. « [Intervjuvanec 4]

Participacija oseb z motnjo v duševnem razvoju bi morala biti izhodišče vsakega umetniškega ustvarjanja. Direktivna razlaga pomena in omejevanje samostojnega iskanja možnih pomenov je namreč ena izmed ovir pri vzgoji skozi umetniško ustvarjanje (Kroflič, 2014). Tudi osebe z motnjo v duševnem razvoju morajo aktivno sodelovati pri načrtovanju in izpeljavi ustvarjanja, saj jim s tem pomagamo, da napredujejo. Mentor mora biti zmožen vključevati udeležence v nastajanje procesa.

\section{Zaupanje, pohvala in realni cilji kot ključni elementi uspešnega mentorstva}

Pohvale so po mnenju intervjuvancev izjemno pomembne pri umetniškem ustvarjanju v skupini oseb z motnjo v duševnem razvoju.

»Zelo radi nastopajo, še rajši pa imajo aplavz na koncu. « [Intervjuvanec 5] Intervjuvanec 1: »Vodi jih nek notranji občutek, ne ženejo se za uspehom, so pa veseli priznanja, pohvale.«

Intervjuvanci poudarjajo, da mentor ne sme imeti nobenih predsodkov, da mora zaupati v svojo skupino: »On bo začutil to, da se trudiš, da verjameš v njega, da vanj zaupaš.« [Intervjuvanec 3] Intervjuvanec 4 poudarja, da je poleg strokovnega znanja izredno pomembno tudi »srce« mentorja, kar pomeni mentorjeve osebnostne značilnosti in profesionalno zavzetost.

»Pri ustvarjanju z njimi moraš biti občutljiv in pozoren. Ne smeř se ukvarjati s končnim izdelkom tako zelo kot s samim procesom.« [Intervjuvanec 3]

Pri umetniškem ustvarjanju v skupini odraslih z motnjo v duševnem razvoju je pomembno, da mentor zaupa v svojo skupino, da zaupa v vsakega posameznika in vanj verjame, kar postavljajo v ospredje tudi drugi avtorji (Klinge, 2015; Krajnc, 2012). Pri tem mora biti mentor usmerjen $\mathrm{k}$ napredovanju in ne $\mathrm{k}$ uspehu, kot bi ga razumeli v kontekstu izobraževanja oseb brez motenj v duševnem razvoju. Kakovost mentorjevega dela izhaja iz obvladovanja procesa ustvarjanja in ne toliko iz končnega izdelka. Mentor si mora postaviti realne cilje in pričakovanja (Gorjup, 2006), predvsem pa mora videti napredek pri vsakem posamezniku, saj so pohvale, kot smo zgoraj omenili, izredno pomembne za razvoj njihove samozavesti.

\section{Kombiniranje različnih aktivnosti kot pogoj za krepitev samozavesti, samostojnosti in socialne vključenosti}

Če mentorji kombinirajo različne vrste umetnosti in različne aktivnosti, povezane z njimi, se kažejo boljši rezultati. Kot nam je zaupal intervjuvanec 2: »Ustvarjanje ob glasbi je način, ki se ga na likovnih delavnicah zelo velikokrat poslužimo, saj glasba naredi prijeten in umirjen ambient, v katerem se uporabniki lažje izrazijo.« Intervjuvanci poudarjajo, da pri likovnem ustvarjanju lahko naredijo inštrumente, scenografijo in maske za dramsko igro, oblačila za plesni nastop. Ko ustvarjajo dramsko igro, lahko to kombinirajo 
s plesno-gibalnimi aktivnostmi, lahko pripravljajo glasbo in besedila. Intervjuvanec 3 pa gre celo dlje od tega: »Kakšna naša dekleta so zelo dobra pri frizurah, se zelo rade ličijo, tako da lahko ustvarijo celotno podobo, ki bo stala na odru.«

Po mnenju intervjuvancev je pomembno, da se mentor zaveda, da gre za socialno učenje, da je to proces, ki poteka v socialnem kontekstu, ki posamezniku omogoči občutek pripadnosti skupini.

Izbrane metode umetniškega ustvarjanja omogočijo krepitev občutka socialne vključenosti, razvoj čuta do sočloveka in pridobivanje samozavesti, kar so po Novljanovi in Jelenčevi (2000) bistvene razvojne naloge, ki jih poskušamo izpolniti z izobraževanjem in učenjem oseb s posebnimi potrebami.

\section{SKLEP}

V zaključku lahko strnemo odgovor na raziskovalno vprašanje, katere so značilnosti mentorjeve vloge pri umetniškem ustvarjanju v skupini odraslih z motnjo v duševnem razvoju. Za mentorsko delo $\mathrm{v}$ teh skupinah so pomembne zmožnost motiviranja posameznikov in skupine, zmožnost vodenja procesa in vključevanja oseb z motnjo v duševnem razvoju v izvajanje umetniških delavnic ter zmožnost vključevanja drugih v timsko delo, predvsem pri individualizaciji dela. Mentor mora znati prilagoditi dejavnosti realni starosti oseb (izogniti se mora pootročenju umetniških delavnic). Odločilnega pomena za uspešno mentorstvo $\mathrm{v}$ skupinah oseb z motnjo $\mathrm{v}$ duševnem razvoju so realno postavljeni cilji in kombiniranje različnih dejavnosti.

$\mathrm{Z}$ raziskavo smo pokazali, da je vloga mentorja pri umetniškem ustvarjanju $\mathrm{v}$ skupini odraslih z motnjo v duševnem razvoju sicer podobna, kot so pokazale raziskave o mentorstvu v drugih skupinah (Findeisen, 2012; Govekar-Okoliš in Kranjčec, 2012, 2013; Klinge, 2015; Opalk 2013), ima pa nekatere značilnosti, ki drugod niso bile raziskane. Pri umetniškem ustvarjanju v skupini oseb z motnjo v duševnem razvoju namreč prideta bolj do izraza timsko delo z drugimi pomočniki (lahko tudi prostovoljci) in individualizacija procesa ustvarjalnih delavnic. Teh ugotovitev ne moremo primerjati $\mathrm{z}$ drugimi raziskavami v slovenskem okolju, ker jih o vlogi mentorja v skupini oseb $\mathrm{z}$ motnjo v duševnem razvoju v Sloveniji še nismo zasledili.

Ugotovitve raziskave so omejene zaradi značilnosti kvalitativne metodologije in majhnega števila intervjujev. Področje bi bilo treba nadalje raziskovati, saj bi potrebovali tudi dodatna usposabljanja za mentorje, ki delajo v skupinah odraslih s posebnimi potrebami. Odgovori intervjuvancev so pokazali, da kljub prepričanju, da je participacija oseb z motnjo v duševnem razvoju izjemno pomembna, te osebe pogosto nimajo možnosti soodločanja, zato bi morali raziskati, na kakšne načine bi jih lahko razmeroma enakovredno vključili v celoten proces. 


\section{LITERATURA}

Allen, T. D. in Eby, L. T. (ur.). (2010). The Blackwell handbook of mentoring: A multiple perspective approach. Malden, Oxford, Carlton: Blackwell.

Aspin, D. N., Chapman, J., Evans, K. in Bagnall, R. (ur.). (2012). Second International Handbook of Lifelong Learning. Dordrecht: Springer.

Brajša, P. (1983). Vodenje kot medosebni proces. Ljubljana: Univerzum.

Brecelj, V., Vidmar, G. in Boštjančič, E. (2014). Načrtovanje kariere invalidov - želje in ovire. Andragoška spoznanja, 20(4), 49-61.

Brookfield, S. (2013). Powerful Techniques for Teaching Adults. San Francisco: Jossey-Bass.

Chng, J. P. L., Stancliffe, R. J., Wilson, N. J. in Anderson, K. (2013). Engagement in retirement: an evaluation of the effect of Active Mentoring on engagement of older adults with intellectual disability in mainstream community groups. Journal of Intellectual Disability Research, 57(12), 1130-1142.

Dremelj, P. (2009). Individualizacija in osebe s posebnimi potrebami. V D. Kobal Grum in B. Kobal (ur.), Poti do inkluzije (str. 29-35). Ljubljana: Pedagoški inštitut.

Farley, J. A., Gibbons, M. M. in Cihak, D. F. (2014). Peer Mentors in a Postsecondary Education Program for Students with Intellectual Disabilities. College Student Journal, 48(4), 651-660.

Findeisen, D. (2012). Kako razumeti mentorsko razmerje in njegove posledice?: Mentorsko razmerje kot sistem znanja, recipročnega učenja, delovanja in odnosov. Andragoška spoznanja, 18(2), 31-42.

Flick, U. (2014). An introduction to qualitative research. Los Angeles: SAGE.

Giust, A. in Valle-Riestra, D. (2014). Supporting Students with Intellectual Disabilities in Higher Education through Mentoring. Pridobljeno s http://digitalcommons.fiu.edu/cgi/viewcontent. cgi? article=1386\& context=sferc.

Gorjup, T. (2006). Vključevanje otrok s posebnimi potrebami pri pouku likovne vzgoje/likovno-terapevtski vidik. V B. Založnik (ur.), Otroci s posebnimi potrebami: integracija in inkluzija (str. 55-62). Nova Gorica: Educa.

Govekar-Okoliš, M. in Kranjčec, R. (2012). Vloga mentorja v izobraževanju starejših odraslih in razvoj mentorskega odnosa. Andragoška spoznanja, 18(2), 43-53.

Govekar-Okoliš, M. in Kranjčec, R. (2013). Uspešnost mentorstva v izobraževanju starejših odraslih. Andragoška spoznanja, 19(3), 80-91.

Grubešič, S. (2014). Posebni program vzgoje in izobraževanja. Ljubljana: Ministrstvo za izobraževanje, znanost in šport: Zavod RS za šolstvo.

Jelenc Krašovec, S. (2005). Osebe z motnjo v duševnem razvoju kot ciljna skupina v izobraževanju odraslih. V V. Bužan, A. Golob, A. Mercina in J. Ulaga (ur.), Odrasle osebe z zmernimi, težjimi in težkimi motnjami v duševnem razvoju: Zbornik prispevkov ob dvajseti obletnici Doma Škofljica, CUDV Dolfke Boštjančič Draga (str. 45-53). Ig: CUDV Dolfke Boštjančič Draga.

Josselson, R. (2013). Interviewing for Qualitative Inquiry. New York: The Guilford Press.

Kačič, M., Bavčar, E. in Sudec Bednařik, K. (2015). Uvodnik: Posebne potrebe niso ovira za umetniško ustvarjanje. V M. Kačič in K. Majerhold (ur.), Umetnost in hendikep: Zbornik prispevkov ob 95. obletnici ZDSSS (5-10). Ljubljana: Rikoss.

Klinge, C. M. (2015). A Conceptual Framework for Mentoring in a Learning Organization. Adult learning, 26(4), 160-166.

Kobal Grum, D. in Kobal, B. (ur.). (2009). Poti do inkluzije. Ljubljana: Pedagoški inštitut.

Konvencija o pravicah invalidov. (2006). Pridobljeno s http://www.mddsz.gov.si/fileadmin/mddsz.gov. si/pageuploads/dokumenti_pdf/konvencija_o_pravicah_invalidov.pdf. 
Krajnc, A. (2012). Individualizacija izobraževanja vodi v mentorstvo: gibanje »Znaš, nauči drugega. Andragoška spoznanja, 18(2), 19-30.

Kroflič, B. (2015). Umetnostna terapija - pomoč z umetnostjo. V M. Peljhan (ur.), Fototerapija: Od konceptov do praks (str. 69-82). Kamnik: Center za izobraževanje, rehabilitacijo in usposabljanje.

Kroflič, R. (2006). Kako udomačiti drugačnost?: Tri metafore drugačnosti v evropski duhovni tradiciji. Sodobna pedagogika, 57(pos. izd.), 26-39.

Kroflič, R. (2014). Vzgoja preko umetniške izkušnje. V K. Majerhold (ur.), Zbornik za spodbujanje demokratičnega emancipiranega dialoga med ponudniki kulturnih dobrin ter obiskovalci (str. 182197). Ljubljana: Društvo ŠKUC, Galerija Škuc.

Kroflič, R., Štirn Koren, D., Štirn Janota, P. in Jug, A. (ur.). (2010). Kulturno žlahtenje najmlajših: Razvoj identitete otrok $v$ prostoru in času preko raznovrstnih umetniških dejavnosti. Ljubljana: Vrtec Vodomat.

Majerhold, K. (ur.). (2014). Zbornik za spodbujanje demokratičnega emancipatornega dialoga med ponudniki kulturnih dobrin ter obiskovalci. Ljubljana: Društvo ŠKUC, Galerija Škuc.

Marinč, D., Burnik, F., Vališer, A., Barborič, K., Potočnik Dajčman, N. in Dretnik, F. (2015). Otroci z motnjami v duševnem razvoju. V N. Vovk-Ornik (ur.), Kriteriji za opredelitev vrste in stopnje primanjkljajev, ovir oz. motenj otrok s posebnimi potrebami (str. 6-7). Ljubljana: Zavod RS za šolstvo.

Može Cedilnik, H. in Uršnik, S. (2011). Otroci z motnjami v duševnem razvoju. V N. Vovk Ornik (ur.), Delo z otroki s posebnimi potrebami (pogl. 13/1). Maribor: Forum Media.

Novljan, E. in Jelenc, D. (2000). Izobraževanje odraslih oseb z motnjami v duševnem razvoju. Ljubljana: Centerkontura.

Opalk, V. (2003). Vloga mentorja in podjetja pri strokovnih praksah: priročnik za usmerjanje mentorjev in vzpostavitev učinkovitega programa strokovne prakse v podjetju. Ljubljana: Pedagoški center Ekonomske fakultete.

Rutar, D. (2015). Sociologija hendikepa in nove družbene prakse. V D. Rutar, R. Kralj in I. Praznik (ur.), Hendikep, delo in družba: Dodatno usposabljanje dijakov s posebnimi potrebami in zagotavljanje kakovosti prehajanja v delovna okolja (str. 7-76). Kamnik: Center za izobraževanje, rehabilitacijo in usposabljanje.

Savage, H., Nováková, P., Holla, J., Sima, A., Burlacu, C., Vilademunt, I., Gutierrez Roca, A., Humisto, T., Latimier, C. in Magri, L. (2013). Advice and guidelines for the peer supporter mentor. Brussels: Inclusion Europe.

Tratnjek, S. in Hameršak, P. (2004). Vloga defektologa v posebnem socialnem zavodu. Pridobljeno s http://www.hrastovec.org/fileadmin/user_upload/dokumenti/Strokovna_knjiznica/Hamer_ak_P._ Tratnjek_S._-_Vloga_defektologa_v_posebnem_socialnem_zavodu.pdf.

Vovk-Ornik, N. (2015). Kriteriji za opredelitev vrste in stopnje primanjkljajev, ovir oz. motenj otrok s posebnimi potrebami. Ljubljana: Zavod RS za šolstvo.

Wilson, N. J., Bigby, C., Stancliffe, R. J., Balandin, S., Craig, D. in Anderson, K. (2013). Mentors“ experiences of using the Active Mentoring model to support older adults with intellectual disability to participate in community groups. Journal of Intellectual and Developmental Disability, 38(4), 344-355.

Zakon o izenačevanju možnosti invalidov. (2010). Pridobljeno s https://www.dz-rs.si/wps/portal/Home/ deloDZ/zakonodaja/izbranZakonAkt?uid=C12563A400338836C12577C80049BDBE\&db=s pr_zak\&mandat=VII.

Založnik, B. (ur.). (2006). Otroci s posebnimi potrebami: integracija in inkluzija. Nova Gorica: Educa. Žagar, D. (2012). Drugačni učenci. Ljubljana: Univerza v Ljubljani, Filozofska fakulteta. 